\title{
Primary Pulmonary MALT Lymphoma about Four Cases and Literature Review
}

\author{
El Haouari $\mathrm{A}^{\mathbf{2}^{\star}}$, Tahiri $\mathrm{L}^{2}$, Moumna $\mathrm{K}^{2}$, Remmilink $\mathbf{M}^{\mathbf{1}}$ and Salmon I \\ ${ }^{1}$ Department of Pathology, Hopital Erasme, Bruxelle, Belgium \\ ${ }^{2}$ Department of Pathology, Hassan li Teaching Hospital, Fez, Morocco
}

\begin{abstract}
Bronchial-associated lymphoid tissue (BALT) lymphoma is a distinct subgroup of low-grade B-cell extranodal nonHodgkin's lymphoma, classified as marginal-zone lymphoma. This study was performed in order to assess the natural history of this rare entity. We evaluated retrospectively the clinical, radiological and histological features and to discuss the optimal management and prognostic factors through a literature review, of 4 patients with biopsy-proven BALT lymphoma collected at department of pathology of Erasme from 2010 to 2014. The group of four patients included tree women and one man, with a median age of 69 years (Range: 45-84 years). One of 4 patients presented fever chest pain within bronchopneumonia, other patients were asymptomatic with an incidental finding after preoperative radiological assessment.

Computed tomography (CT), which is more sensitive than standard radiography, has demonstrated that the lesions are unilateral $(n=3)$ and multiple (1 patient), without lymph node enlargement. All of our patients has a thoracoscopy diagnosis and therapeutic. Macroscopy: whitish lesions poorly defined. Microscopy: MALT Iymphoma low grade (CD20 $+, \mathrm{bcl} 2+)$. All of our patients have just a local treatment without chemotherapy and three were alive after a follow extended.
\end{abstract}

Keywords: Lung; Extranodal marginal zone/lowgrade B-cell lymphoma of MALT type

Abbreviation: MALT: Mucosa-Associated Lymphoid Tissue; NSCLC: Non-Small-Cell Carcinoma; HP: Helicobacter pylori; NHL: Non-Hodgkin's Lymphoma; BALT: Bronchus-Associated Lymphoid Tissue

\section{Introduction}

Mucosa-associated lymphoid tissue-derived (MALT) lymphoma is the most frequent subset of primary pulmonary lymphoma (PPL), and lung location represents $15 \%$ of cases [1-5]. Clinical presentation is not specific, and $36 \%$ of the patients are asymptomatic [5-12]. Diagnosis should be suspected in patients with chronic alveolar opacity, usually with an air bronchogram and no pleural effusion or mediastinal adenopathy $[9,10,12,13]$.

Diagnosis requires biopsies such as bronchial, transbronchial, percutaneous or even invasive methods such as surgical open lung biopsies for histological analysis and immunohistologicalstaining. Histologically, primary pulmonary MALT-type lymphoma is characterized by a lymphoplasmacytic infiltrate with reactive germinal centers and the presence of lymphoepithelial lesions. There is no consensus on treatment. Current options are surgery, chemotherapy and radiotherapy.

\section{Patients and Methods}

We found four cases of PMALT (0.17\%) from 2250 lung cancer collected at department of pathology of Erasme from 2010 to 2014.

\section{Case 1}

A 45 years-old woman, asymptomatic, who asked her doctor following the discovery of tuberculosis in a colleague of her husband, the realization of a chest X-ray showed right pulmonary condensation. Chest CT found a pulmonary mass in the right middle lobe hypermetabolic at PET scan (Figure 1). There was no lymph node or pleural abnormalities. No distant metastasis was evident. Transbronchial biopsy: large cell carcinoma (NSCLC). A sleeve right middle lobectomy and total dissection of the regional lymph nodes was performed through a right thoracotomy for cancer staging.

\section{Pathological examination:}

Macrosscopy: Condensation poorly defined extent of $3 \mathrm{~cm}$.

Microscopy: Low grade BALT $(\mathrm{CD} 20+, \mathrm{bcl} 2+)$ invading the bronchial and vascular margins (Figure 2).

Later the patient was referred to the oncology service. There is no recurrence at 12 months.

\section{Case 2}

A 82 years-old woman with a history of rheumatoid arthritis, was admitted to our hospital for investigation of an abnormal chest shadow (a localized alveolar opacity with an air bronchogram) in preoperative chest radiography of a cure of tunnel carpien.

Chest CT shows a pulmonary mass in the upper right lobe, $6 \mathrm{~cm}$ long axis hypermetabolic at PET scan. There was no lymph node or pleural abnormalities. No distant metastasis was evident.

The decision of the meeting of the multidisciplinary discussion (RCP) is the realization of a right anterior segmentectomy and tumoral analyze on intraoperative rapid frozen section examination. The pathological diagnosis was MALT lymphoma (CD79a+, CD20+, Ki67<2\%, CK stain lymphoepithelial lesions). Vascular and bronchial

${ }^{*}$ Corresponding author: Aziza El Haouari, Department of Pathology, Hassan li Teaching Hospital, Fez, Morocco, Tel: +212 72400059; E-mail: nawalaziza@ hotmail.fr

Received Febuary 25, 2015; Accepted December 29, 2015; Published December 31,2015

Citation: El Haouari A, Tahiri L, Moumna K, Remmilink M, Salmon I (2015) Primary Pulmonary MALT Lymphoma about Four Cases and Literature Review. J Pulm Respir Med 5: 307. doi:10.4172/2161-105X.1000307

Copyright: (C) 2015 El Haouari A, et al. This is an open-access article distributed under the terms of the Creative Commons Attribution License, which permits unrestricted use, distribution, and reproduction in any medium, provided the original author and source are credited. 


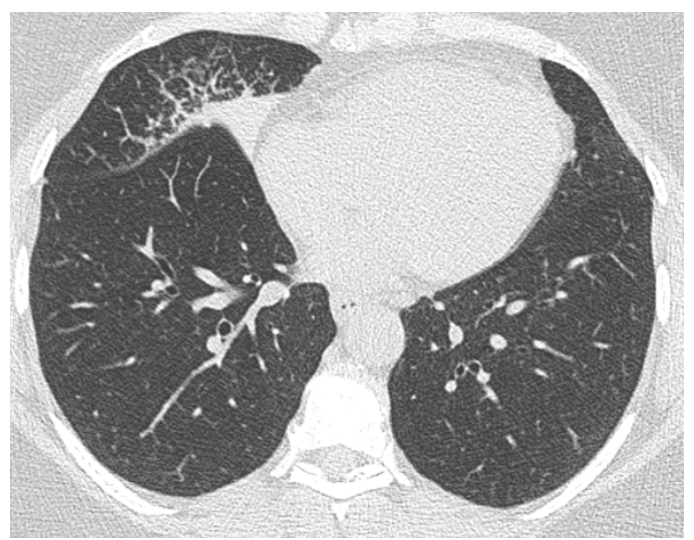

Figure 1: CT scan: pulmonary mass $3 \mathrm{~cm}$ long axis in the right middle lobe (case 1).

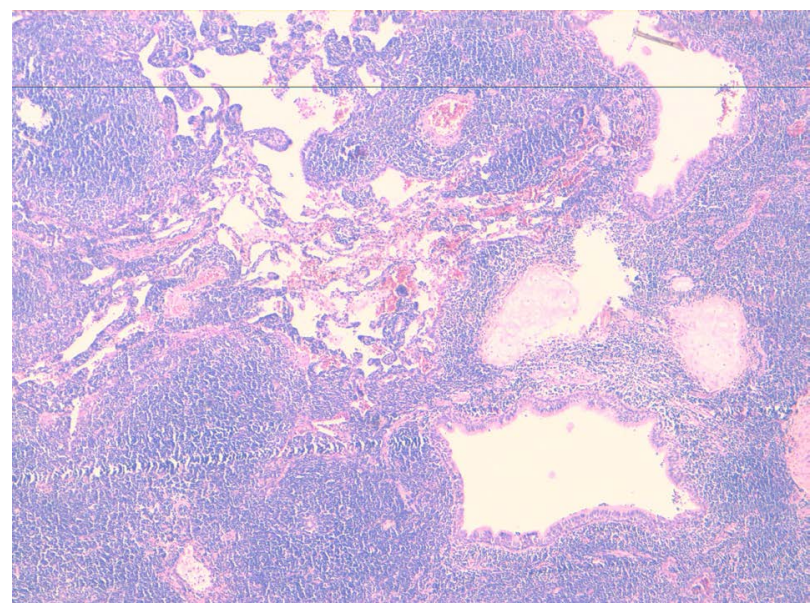

Figure 2: HES x 5: LMALT invading the bronchial and vascular margins (case 1).

margins were no tumor.

Routine hematology and serology showed neither a lymphocytosis nor an abnormal paraprotein band. The post-operative course of the patient was uneventful and she has been free from the disease until now (2 years)

\section{Case 3}

A 84 years old woman has been history of bronchopneumonia in repetition. Chest radiography showed a left alveolar opacity with blurred contours.

In this context, a CT scan was performed and showed the presence of a spike nodule measuring $1.2 \mathrm{~cm}$ long axis, in the anterior segment of the left upper lobe. The PET scan showed an abnormality in this segment, discreetly hypermetabolic, which neoplastic nature could not be excluded.

Transbronchial lung biopsy (TBLB) showed chronic inflammatory alteration; lymphoproliferative process to eliminate. Immunohistochemistry study non-contributory for lack of material.

The patient underwent video-assisted thoracoscopic lingulectomie. The pathological examination is consistent with BALT lymphoma type of low grade whose resection is complete. Periodic following was decided, given the good evolution (3 years).

\section{Case 4}

A 68 years-old men, had no other medical history, admitted to our institution for the management of a left cerebral frontotemporal hemorrhage with mass effect and involvement in falcoriel, diagnosed in cerebral scanner performed in the context of loss of consciousness.

Chest CT showed pulmonary infiltrates in the right lower lobe and the left uper lobe with an air bronchogram clearly visible on chest radiography (Figures 3-9).

On the second day of admission, he developed sudden onset of dyspnea followed by cardiorespiratory arrest and succumbed despite resuscitative measures.

An autopsy was performed after obtaining written consent.

\section{Macroscopy}

- 2 large whitish lesion $4.5 \mathrm{~cm}$ and $2 \mathrm{~cm}$ longer axis located at the lower right lung lobe and whitish lesion $2.5 \mathrm{~cm}$ in the left upper lobe.

- Whitish liver lesion $2 \mathrm{~cm}$ in the Segment VI

- Diffuse whitish thickening of the gastric wall.

- Capsular thickening and whitish splenic lesion $3 \mathrm{~cm}$ longer axis.

Microscopy: lung, gastric, splenic, hepatic and medullar localization of a MALT lymphoma.

\section{Discussion}

PPL is very rare. While extranodal forms represent $24-50 \%$ of cases of NHL [1-3], PPL represent only $3-4 \%$ of extranodal NHL, $<1 \%$ of NHL, and only $0.5-1 \%$ of primary pulmonary malignancies $[1,4,5]$. Primary pulmonary NHL is most commonly represented by marginal zone B-cell lymphoma (MALT lymphoma) [1].

In our series, PMALT ( 4 cases) represents $0.7 \%$ of all lung cancers (2250 cases) diagnosed in our institution from 2010 to 2014.

MALT is a lymphoid tissue specializing in mucosal defense [1]. It was first described in the gastrointestinal tract of animal models, then in the human ileum.

The stomach is the most frequent site of MALT lymphoma and serves as a model for pulmonary MALT lymphoma. As in the stomach,

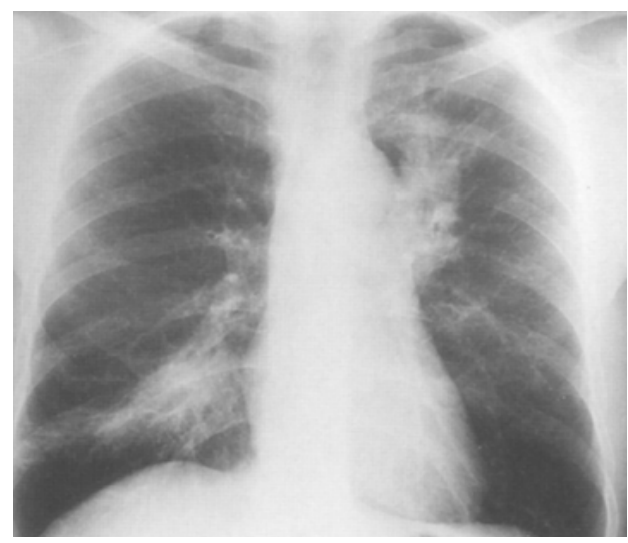

Figure 3: Chest radiography: infiltrates in the right lower lobe and the left upper lobe with a with an air bronchogram (case 4). 
Citation: El Haouari A, Tahiri L, Moumna K, Remmilink M, Salmon I (2015) Primary Pulmonary MALT Lymphoma about Four Cases and Literature Review. J Pulm Respir Med 5: 307. doi:10.4172/2161-105X.1000307

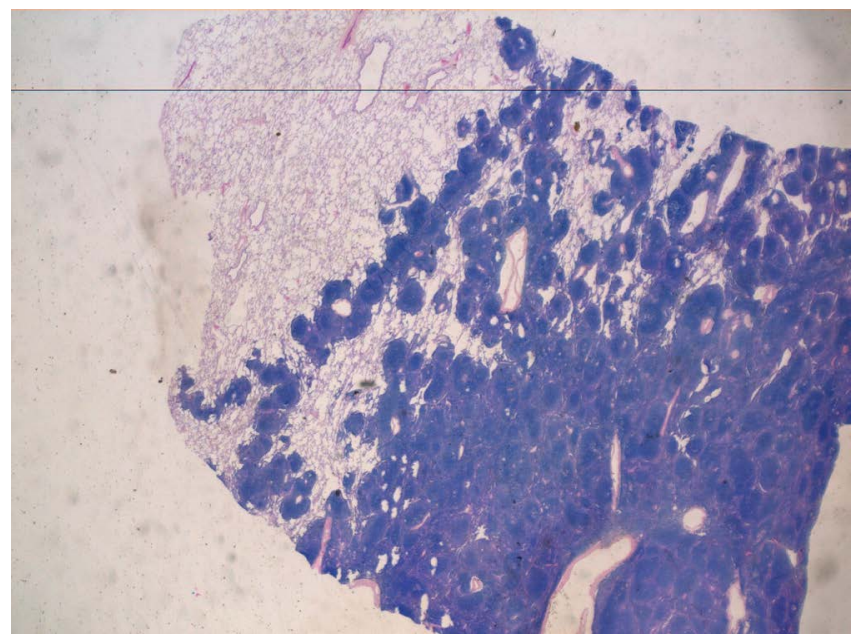

Figure 4: HES x 2: Proliferation of small lymphoid cells analogous to the marginal zone cells of Peyer's patches or spleen follicles.

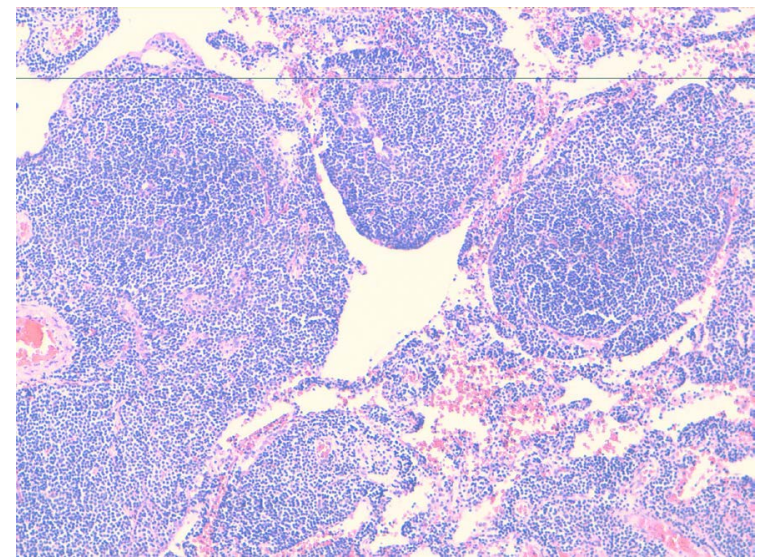

Figure 5: HES x 20: Reactive follicular hyperplasia.

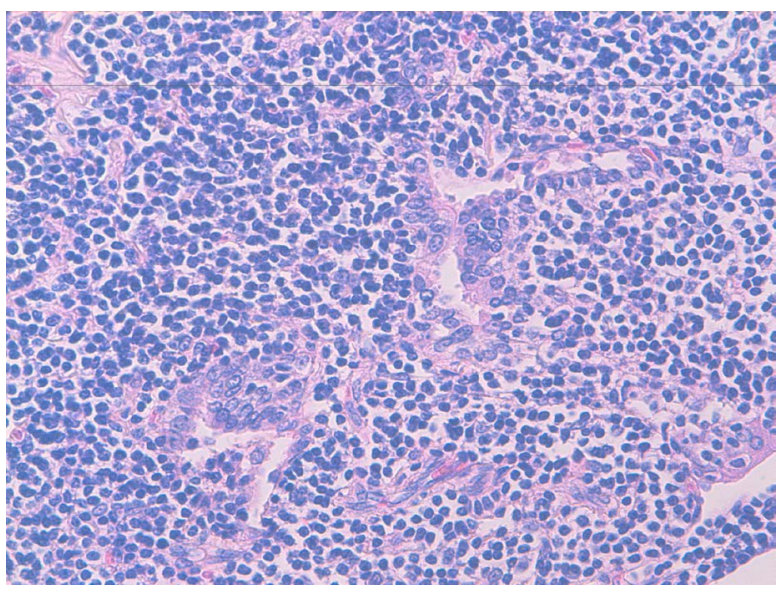

Figure 6: HES x 40: Lymphoepithelial lesions.

MALT is absent from the lung in physiological circumstances. During chronic antigenic stimulation (by Helicobacter pylori, for example), MALT can develop in the stomach and undergo secondary

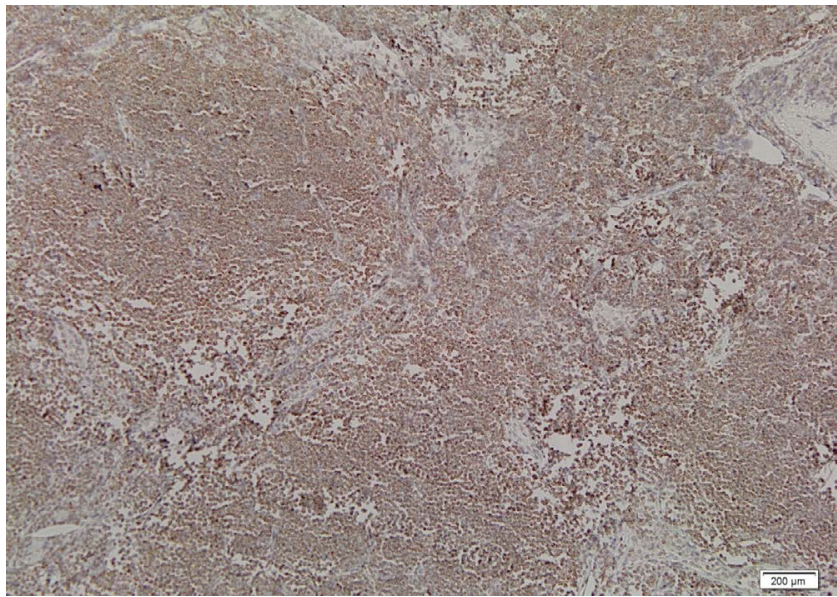

Figure 7: BCL2 (+) (case1).

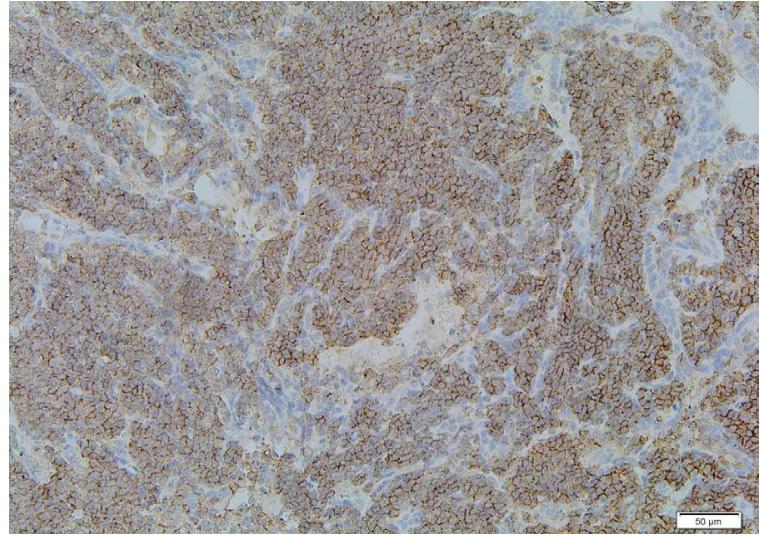

Figure 8: CD20 (+) (case 1).

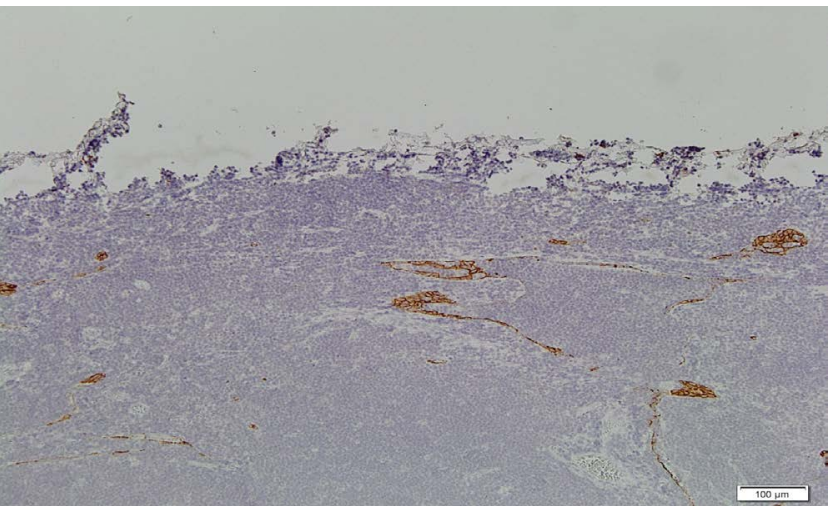

Figure 9: Lymphoepithelia lesions CK (+) (case 2).

lymphomatous transformation arising from marginal zone B-cells.

No triggering antigens have so far been identified in the lung, but chronic antigenic stimulation in certain autoimmune disorders (systemic lupus erythematosus, rheumatoid arthritis, Hashimoto's thyroiditis and particularly Gougerot-Sjögren's syndrome) are considered to affect the onset of pulmonary MALT lymphoma [6].

In the present cases, one patient (case 2) had a history of a rheumatoid 
arthritis. Age of onset is $\sim 50-60 \mathrm{yrs}(12-79 \mathrm{yrs})$ and subjects $<30 \mathrm{yrs}$ are rarely affected [5,7-12]. The two sexes are equally affected [5,7-12]. In our series median age is 69 years (Range: $45-84$ years) and the sex ratio was $3 \mathrm{~F} / 1 \mathrm{H}$. Nearly half these patients are asymptomatic at diagnosis and are identified fortuitously on the basis of a radiological pulmonary anomaly $[5,8-10,12]$. When present, symptoms, such as cough, mild dyspnoea, chest pain and occasionally haemoptysis, are non specific [5,7-12]. By definition, extra-pulmonary manifestations are restricted to general signs (fever and weight loss) and occur in less than one quarter of patients $[5,8-10,12]$. In our series, 3 patients were asymptomatic and one patient has fever chest pain within bronchopneumonia.

The usual radiological aspect $(50-90 \%$ of cases) is a localized alveolar opacity, with a diameter of $<5 \mathrm{~cm}$ and blurred or well-defined contours (according to the series); it is associated in nearly $50 \%$ of cases with an air bronchogram (Figure 3) $[9,10,12]$.

In our series, all patients have an alveolar opacity in the chest radiography and 2 cases (50\%) with an air bronchogram.

Computed tomography (CT) (Figure 1), which is more sensitive than standard radiography, has demonstrated that the lesions are usually bilateral (60-70\%) and multiple (70-77\%) [13]. Nearly all these lesions contain clear areas corresponding to an intact bronchial lumen (Figure 3). The presence of distended bronchi within the lesions is a good diagnostic sign, although the underlying mechanism is unexplained [13]. Less than $10 \%$ of patients have bilateral diffuse reticulonodular opacities, atelectasia or pleural effusion $[9,10,12]$. CT scan reveal hilar and mediastinal adenopathy $[7,12]$. In our series, only one patient (case 4) had bilateral and multiple lesions in CT scan, no patient had a pleural effusion or médiastinal lymphadenopathy.

Bronchial endoscopy usually shows a normal macroscopic aspect [12], although abnormalities ranging from mucosal inflammation to bronchial stenosis can be observed [12]. The diagnostic yield of bronchial, and especially transbronchial, biopsy is higher when it targets visible endobronchial lesions or radiographic abnormalities [12]. However, the absence of specific signs in most of these samples necessitates further diagnostic investigations [5,7-12].

In our series, 2 patients underwent transbronchial biopsy could not conclude an accurate diagnosis. (case1: NSCLC; case 3: chronic inflammatory alteration, lympho-proliferative process to eliminate). Usually, the diagnosis of MALT-type NHL is based on histological examination of surgical samples or transthoracic biopsy material.

The macroscopic aspect is that of a whitish, soft and poorly-defined mass. Microscopically, MALT-type PPL is defined as a lesion $[8,9,14-$ 16] containing: 1) proliferation of small lymphoid cells analogous to the marginal zone cells of Peyer's patches or spleen follicles, centrocytelike cells and small lymphocytes, plasmocytes or monocytoid cells; 2) a lymphoepithelial lesion showing lymphoid cell migration from the marginal zone to the bronchiolar epithelium; 3) reactive follicular hyperplasia; and 4) rare blastic cells. More unusual features include amyloid deposits $(10,43)$ and granulomatous deposits [17-19]. Various degrees of fibrosis can be found. Lymphomatous infiltration causes smooth or nodular interstitial thickening with a peribronchovascular distribution [18] (Figure 3).

Immunohistochemical analysis contributes to the differential and positive diagnosis of MALT-type PPL. It shows the B-cell phenotype (CD19, CD20) [5,8] and clonal nature [14,15] of the lymphoid infiltrate invading follicular structures and invading the bronchial/ bronchiolar epithelium (Figure 3). It also reveals, by the persistence of dendritic cells (CD21, CD35), the presence, within the tumoural proliferation, of destroyed follicles, together, in most cases, with small reactive $\mathrm{T}$ lymphocytes $(\mathrm{CD} 3)$ in the alveolar wall infiltrate and around peribronchiolar nodules $[18,15]$. Above all, immunohistochemical tests can rule out low-grade lymphoma (centrofollicular NHL-B, mantel NHL-B and chronic lymphocytic leukemia (CLL)-type lymphoma) by showing the lack of CD5 and CD10 surface antigens [18,15,20,21].

In our series, the histological appearance was suggestive of MALT lymphoma (proliferation of small cells with lymphoepithelial lesions) and immunohistochemical pannel used included: CD20(+), CD3(-), bcl2 (+), CD10(-), CD5(-)

Although bone marrow involvement is far more frequent in lymphoma of the nodal or splenic marginal zone [22], bone marrow biopsy is crucial, showing signs of invasion in $\leq 20-30 \%$ of patients in recent series of MALT lymphoma [23,24]. Similarly, these series showed concomitant involvement of other mucosal lymphoid sites in $25-35 \%$ of cases [25], and even more frequently in patients with MALT lymphoma not involving the gastrointestinal tract.

In our series, one patient had simultaneous lung, gastric, splenic, hepatic and medullar localization of a MALT lymphoma.

The outcome of MALT-type PPL is generally favorable in most series, with a 5 -yr survival rate of $>80 \%$ and a median survival time of $>10$ yrs $[5,7-9,14,12]$.

There is no consensus on treatment. The lack of an identified culprit antigen in the lung, contrary to the stomach (H. pylori), means that antibiotics effective on low-grade localized gastric lymphoma are inappropriate. Current treatment options are surgery, chemotherapy and radiotherapy $[5,7,8,10]$. The respective efficacy of these treatments cannot be analysed, however, owing to a lack of comparative series, and some authors even propose simple clinical monitoring [8] Nevertheless, surgical resection is commonly preferred for localized tumors $[5,7,8,10]$. Exclusive chemotherapy is generally used for patients with bilateral or extrapulmonary involvement, relapse or progression.

In the present cases, 3 of our patients have localized tumors, were have just a local treatment and all were alive after a follow extended.

\section{Conclusion}

The MALT primary lung lymphoma must not be underestimated. Clinical manifestations and radiological characteristics are no specific. Usually, the diagnosis of MALT-type NHL is based on histological examination of surgical samples or transthoracic biopsy material. There is no consensus on treatment. Nevertheless, surgical resection is commonly preferred for localized tumors. Although our series is small, the clinical and imaging features were consistent with those described in the literature, the prognosis was favorable even the follow-up is still short and the treatment was exclusively based on surgery.

\section{References}

1. Isaacson PG, Norton AJ (1994) Extranodal lymphomasNew York, Churchill Livingstone.

2. Freeman C, Berg JW, Cutler SJ (1972) Occurrence and prognosis of extranodal lymphomas. Cancer 29: 252-260.

3. Newton R, Ferlay J, Beral V, Devesa SS (1997) The epidemiology of nonHodgkin's lymphoma: comparison of nodal and extra-nodal sites. Int J Cancer 72: 923-930.

4. Clagett OT, Allen TH, Payne WS, Woolner LB (1964) The surgical treatment of pulmonary neoplasms: a 10-year experience. J Thorac Cardiovasc Surg 48: 391-400.

5. L'Hoste RJ Jr, Filippa DA, Lieberman PH, Bretsky S (1984) Primary pulmonary 
Citation: El Haouari A, Tahiri L, Moumna K, Remmilink M, Salmon I (2015) Primary Pulmonary MALT Lymphoma about Four Cases and Literature Review. J Pulm Respir Med 5: 307. doi:10.4172/2161-105X.1000307

lymphomas. A clinicopathologic analysis of 36 cases. Cancer 54: 1397-1406.

6. Dogan A, Isaacson PG (2003) Splenic marginal zone lymphoma. Semin Diagn Pathol 20: 121-127.

7. Kennedy JL, Nathwani BN, Burke JS, Hill LR, Rappaport H (1985) Pulmonary lymphomas and other pulmonary lymphoid lesions. A clinicopathologic and immunologic study of 64 patients. Cancer 56: 539-552.

8. Addis BJ, Hyjek E, Isaacson PG (1988) Primary pulmonary lymphoma: a re-appraisal of its histogenesis and its relationship to pseudolymphoma and lymphoid interstitial pneumonia. Histopathology 13: 1-17.

9. Herbert A, Wright DH, Isaacson PG, Smith JL (1984) Primary malignan lymphoma of the lung: histopathologic and immunologic evaluation of nine cases. Hum Pathol 15: 415-422.

10. Le Tourneau A, Audouin J, Garbe L (1983) Primary pulmonary malignan lymphoma, clinical and pathological findings, immunocytochemical and ultrastructural studies in 15 cases. Hematol Oncol 1: 49-60.

11. Peterson H, Snider HL, Yam LT, Bowlds CF, Arnn EH, et al. (1985) Primary pulmonary lymphoma. A clinical and immunohistochemical study of six cases. Cancer 56: 805-813.

12. Cordier JF, Chailleux E, Lauque D, Reynaud-Gaubert M, Dietemann-Molard A, et al. (1993) Primary pulmonary lymphomas. A clinical study of 70 cases in nonimmunocompromised patients. Chest 103: 201-208.

13. Wislez M, Cadranel J, Antoine M, Milleron B, Bazot M, et al. (1999) Lymphoma of pulmonary mucosa-associated lymphoid tissue: CT scan findings and pathological correlations. Eur Respir J 14: 423-429.

14. Li G, Hansmann ML, Zwingers T, Lennert K (1990) Primary lymphomas of the lung: morphological, immunohistochemical and clinical features. Histopathology 16: $519-531$

15. Nicholson AG, Wotherspoon AC, Diss TC, Butcher DN, Sheppard MN et al. (1995) Pulmonary B-cell non-Hodgkin's lymphomas. The value of immunohistochemistry and gene analysis in diagnosis. Histopathology 26
395-403.

16. Isaacson PG (1991) B cell lymphomas of mucosa associated lymphoid tissue (MALT). Bull Cancer 78: 203-205

17. Koss MN, Hochholzer L, Nichols PW, Wehunt WD, Lazarus AA (1983) Primary non-Hodgkin's lymphoma and pseudolymphoma of lung: a study of 161 patients. Hum Pathol 14: 1024-1038.

18. Fiche M, Caprons F, Berger F, Galateau F, Cordier JF, et al. (1995) Primary pulmonary non-Hodgkin's lymphomas. Histopathology 26: 529-537.

19. Turner RR, Colby TV, Doggett RS (1984) Well-differentiated lymphocytic lymphoma. A study of 47 patients with primary manifestation in the lung. Cancer 54: 2088-2096.

20. Harris NL, Isaacson PG (1999) What are the criteria for distinguishing MALT from non-MALT Iymphoma at extranodal sites? Am J Clin Pathol 111: S126132.

21. Dorfman DM, Pinkus GS (1995) Utility of immunophenotypic studies in the diagnosis of low-grade lymphoma of mucosa-associated lymphoid tissue (MALT) and other low-grade non Hodgkin's lymphomas of extra-nodal sites. Appl Immunohistochem 3: 160-167.

22. Nathwani BN, Anderson JR, Armitage JO (1999) Marginal zone B-cell lymphoma: A clinical comparison of nodal and mucosa-associated lymphoid tissue types. Non-Hodgkin's Lymphoma Classification Project. J Clin Oncol 17 2486-2492.

23. Zinzani PL, Magagnoli M, Galieni P, Martelli M, Poletti V, et al. (1999) Nongastrointestinal low-grade mucosa-associated lymphoid tissue lymphoma: analysis of 75 patients. J Clin Oncol 17: 1254

24. Thieblemont C, Berger F, Dumontet C (2000) Mucosa-associated lymphoid tissue lymphoma is a disseminated disease in one third of 158 patients analyzed. Blood 95: 802-806.

25. Yousem SA, Colby TV (1991) Pulmonary lymphomas and lymphoid hyperplasias In: Knowles DM, ed. Neoplastic HematopathologyBaltimore Williams and Wilkins pp. 979-1007. 